\title{
Originals
}

\section{Recovery by mouse embryos following teratogenic exposure to ketosis}

\author{
L. Shum and T. W.Sadler \\ Department of Cell Biology and Anatomy, Laboratories for Developmental Biology, The School of Medicine, \\ The University of North Carolina at Chapel Hill, North Carolina, USA
}

\begin{abstract}
Summary. Previous studies have shown that the ketone body $\mathrm{D}, \mathrm{L},-$ beta-hydroxybutyrate was teratogenic to mouse embryos exposed in culture during the period of neurulation. Inhibition of closure of the cranial and caudal neuropores was the most frequently occurring defect and these abnormalities were thought to be the forerunner of anencephaly and spina bifida, respectively. However, additional studies demonstrated that embryos could recover morphologically from these effects if the ketone body was removed from the culture medium and if the recovery period was of sufficient duration. In an attempt to define further the phenomenon responsible for this recovery and to determine the extent of the recovery process, the present study examining the cross-sectional area, cell number, and mitotic index of cranial neuroepithelial cells was conducted in mouse embryos cultured from the early somite stage under one of the following conditions: 1) control medium for $60 \mathrm{~h}$; 2) medium containing $32 \mathrm{mmol} / \mathrm{l} \mathrm{D}, \mathrm{L}$,-beta- hydroxybutyrate for $24 \mathrm{~h}$ followed by culture in control medium for an additional $36 \mathrm{~h}$ (recovery
\end{abstract}

group); 3) medium containing $32 \mathrm{mmol} / 1 \mathrm{D}, \mathrm{L}$,-beta-hydroxybutyrate for $60 \mathrm{~h}$ (continuously exposed group). The results indicate that although neural tube closure occurred in the recovery group, complete recovery was limited to the ventral regions of the forebrain and that the remainder of the prosencephalon as well as the rhombencephalon failed to undergo complete catch-up growth. Thus, cell numbers in these areas were approximately $70 \%$ of control values. Therefore, while the gross anatomical disturbances produced by the ketone body may be compensated for, histological alterations in the affected tissues remain. Ultimately, these data suggest that neurological deficits may be an outcome of ketone body exposure during the early stages of embryogenesis.

Key words: D,L,-beta-hydroxybutyrate, diabetic embryopathy, ketosis, diabetes neural tube defects, anencephaly, spina bifida.
Several studies have investigated the potential for catch-up growth to occur following a prenatal insult. However, these studies have focussed on the effect of insults occurring during early periods of embryogenesis, i. e. prior to gastrulation [1], or late embryonic and fetal stages [2-4]. Thus, very little is known about the capacity for embryonic recovery during the period of organogenesis or the mechanisms involved in such catch-up growth. In fact, it is generallystated that if a particular event in organogenesis is disrupted in space and time, then an abnormality in that organ system will occur [5]. However, recent results from our laboratory involving the teratogenicity of $\mathrm{D}, \mathrm{L}$,-beta-hydroxybutyrate (BOHB) in neurulating mouse embryos in vitro demonstrated a great potential for embryonic recovery following exposure to concentrations of the compound that inhibited neural tube closure, craniofacial development, somite formation and growth in all exposed embryos [6]. Such data suggest that the ketone alone may not be a major factor in producing gross malformations in infants of diabetic mothers. However, reports linking ketotic episodes to low brain weights $[7,8]$ and neurological deficits in offspring from diabetic mothers raised concern that histological recovery may not have been as complete as that observed for morphology. Therefore, the following study involving an assessment of morphometry, cell number and mitotic indices in normal embryos and those recovering from $\mathrm{BOHB}$ exposure was conducted.

\section{Materials and methods}

\section{Whole embryo culture and experimental protocol}

Random bred ICR mice (Harlan Sprague-Dawley, Ind., USA) were kept on a $14 \mathrm{~h}$ light, $10 \mathrm{~h}$ dark cycle, fed with laboratory chow and water ad libitum. Mating was allowed by placing one male with four 
females for $4-5 \mathrm{~h}$. Successful mating was indicated by the presence of a vaginal sperm plug and this day was designated day 1 of gestation.

Whole embryo culture was performed under sterile conditions as described previously [9-11]. Briefly, day 9 pregnant mice were killed by cervical dislocation, uterine horns were removed and implantation sites were separated from one another. Following removal of the uterine tissue, decidua, trophoblast and Reichert's membrane, conceptuses which now consisted of embryo, visceral yolk sac, and ectoplacental cone were individually grown in $2.5 \mathrm{ml}$ of culture medium in a $30 \mathrm{mlculture}$ flask and mounted on a rotating wheel at $30 \mathrm{rev} / \mathrm{min}$ at $37^{\circ} \mathrm{C}$. Cultures were gassed twice a day $10-14 \mathrm{~h}$ apart with a mixture of $5 \% \mathrm{O}_{2}, 5 \% \mathrm{CO}_{2}$, and $90 \% \mathrm{~N}_{2}$ on gestation day $9 ; 20 \% \mathrm{O}_{2}, 5 \% \mathrm{CO}_{2}$, and $75 \% \mathrm{~N}_{2}$ on day 10 ; and $95 \% \mathrm{O}_{2}$, and $5 \% \mathrm{CO}_{2}$ on day 11 .

Mouse embryos of 2-3 somites were used and randomly assigned to one of three groups: Group A (control group), Group B (recovery group) and Group C (continuously exposed group). During the first 24 h of culture, designated Period I, Group A was cultured in control medium which consisted of $75 \%$ immediately centrifuged, heat inactivated rat serum and $25 \%$ Tyrode's phosphate buffer. Groups B and $C$ were grown in medium of the same composition with an addition of $32 \mathrm{mmol} / 1 \mathrm{BOHB}$ (Sigma Chemical Company, St. Louis, Mo., USA). This concentration was selected because previous studies have shown that BOHB can induce neural tube defects in a dose-dependent manner from $8-32 \mathrm{mmol} / \mathrm{l}$ and that the $32 \mathrm{mmol} / \mathrm{l}$ concentration produces the abnormality in $100 \%$ of the embryos [12-14]. At the end of Period I, all the embryos were removed, rinsed in three changes of sterile Tyrode's buffer at $37^{\circ} \mathrm{C}$, and transferred to fresh medium. Groups A and B were then cultured in control medium, whereas Group C remained exposed to $32 \mathrm{mmol} / \mathrm{l} \mathrm{BOHB}$. All embryos were grown for a maximum of $36 \mathrm{~h}$ and this second period of culture was designated Period II. Thus, Group A was the control group because it was cultured in normal control medium during both Periods I and II; Group B was the recovery group since it was exposed to $\mathrm{BOHB}$ during Period $\mathrm{I}$, but subsequently transferred to control medium during Period II; Group C served as another reference group for it was continuously exposed to the ketone body throughout the entire period of study.

During Period II, all embryos were terminated at one of four time points; $0,12,24$ or $36 \mathrm{~h}$. Zero hour was actually the conclusion of Period I (i.e. treatment period) and $36 \mathrm{~h}$ was the conclusion of Period II (i.e. recovery period). Representative specimens were processed for scanning electron and light microscopy.

\section{Scanning electron microscopy}

Specimens were fixed in $2.5 \%$ glutaraldehyde in Sorenson's buffer (0.1 mol/l sodium phosphate buffer) [15] at $\mathrm{pH} 7.3$ for 1 day to 2 weeks. Embryos were then rinsed in three changes of buffer, and postfixed in $2 \%$ osmium tetroxide in Sorenson's phosphate buffer. Subsequently, the tissues were rinsed and then dehydrated with increasing grades of ethanol; $25 \%, 50 \%, 70 \%, 80 \%, 95 \%$ and three changes of $100 \%$, each $15 \mathrm{~min}$. Afterwards, embryos were critical point dried with a Balzers Union $\mathrm{CPD}-010$ using liquid $\mathrm{CO}_{2}$, mounted on metal stubs, gold-palladium sputter coated with a Polaron Instruments E5100, and examined with a JOEL 35 Scanning Electron Microscope.

\section{Light microscopy}

Specimens were fixed in modified Karnovsky's fixative [16], a $2 \%$ paraformaldehyde and $2 \%$ glutaraldehyde solution with $0.01 \% \mathrm{cal}-$ cium chloride in $0.1 \mathrm{~mol} / 1$ sodium cacodylate buffer $(\mathrm{pH} 7.3)$ for 1 to $1.5 \mathrm{~h}$. After fixing, embryos were rinsed twice in $0.1 \mathrm{~mol} / \mathrm{l}$ buffer and postfixed in $1 \%$ osmium tetroxide in $0.1 \mathrm{~mol} / \mathrm{l}$ sodium cacodylate buffer. Subsequently, tissues were rinsed and dehydrated in an upgraded series of ethanol; $70 \%, 90 \%, 100 \%$, two changes each of 10 to $15 \mathrm{~min}$, followed by two changes of propylene oxide. Specimens were then infiltrated and embedded in Araldite. Blocks were

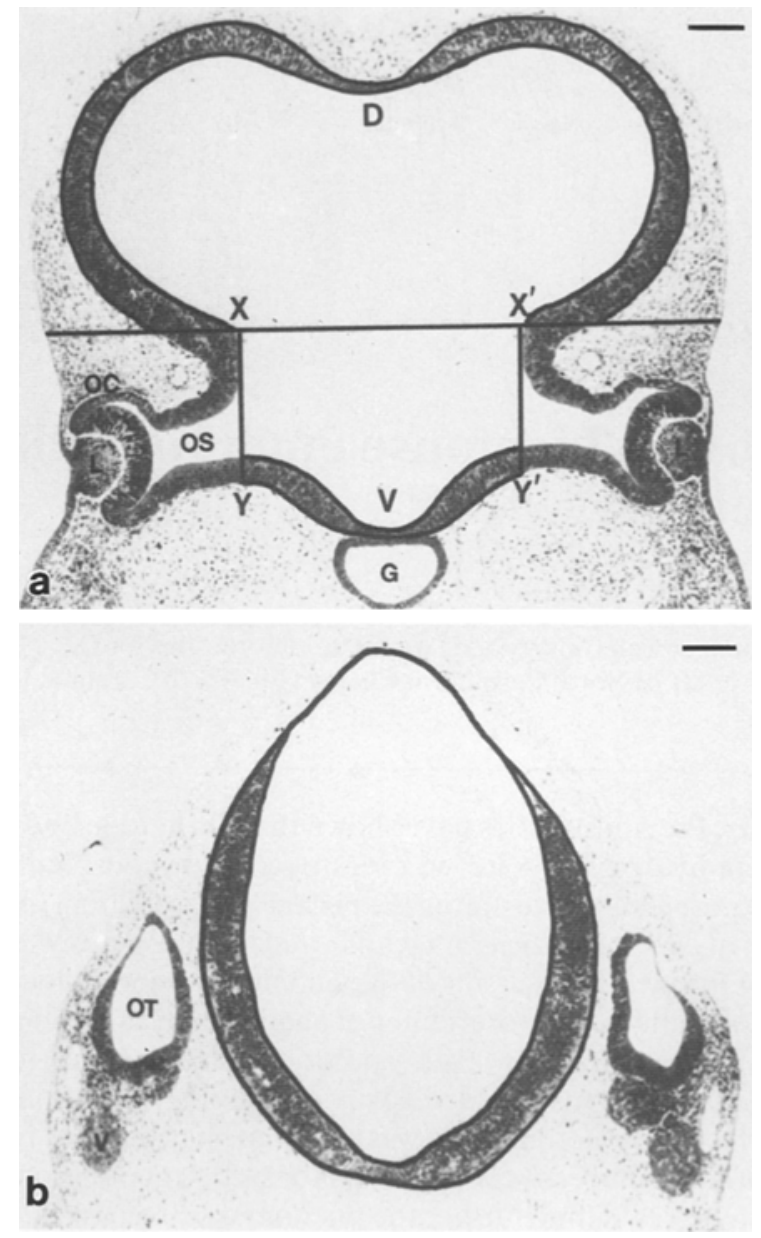

Fig.1a,b. Morphometric delineation of the prosencephalic and rhombencephalic neuroectoderm. a Histological cross-section at the level of the developing optic vesicles of Group A control mouse embryo at the $36 \mathrm{~h}$ time point of Period II (i. e. cultured in control medium for a total of $60 \mathrm{~h}$ starting from the $2-3$ somite stage). The dorsal and ventral regions of the neuroepithelium were demarcated by first drawing a horizontal line joining $X$ and $X^{\prime}$ which were points of inflections of the neuroepithelium where the optic stalks (OS) and optic cups (OC) arose. Then, two perpendicular lines were drawn with respect to line $X X^{\prime}$ to intersect with the ventral side of the neuroepithelium at $Y$ and $Y^{\prime}$. Therefore, the dorsal region of the prosencephalon ( $\mathrm{D}$; outlined in bold) was defined as the portion dorsal to line $\mathrm{XX}^{\prime}$ and the ventral region (V; outlined in bold) as the portion between points $\mathrm{YY}^{\prime} . \mathrm{G}=$ pharyngeal gut tube; $\mathrm{L}=$ lens vesicles. Scale bar $=0.1 \mathrm{~mm}$. b Histological cross-section at the level of the developing otic vesicles of Group A control mouse embryo at the $36 \mathrm{~h}$ time point of Period II (i. e. cultured in control medium for a total of $60 \mathrm{~h}$ starting from the 2-3 somite stage). Analyses of mean cross-sectional area, mean cross-sectional cell number and mitotic index were performed on the entire neuroepithelium (outlined in bold). $O T=$ otic vesicle; $V=$ vestibulocochlear ganglion. Scale bar $=0.1 \mathrm{~mm}$

trimmed and sectioned with an LKB Ultramicrotome V. Sections of $1 \mu$ thickness were obtained, stained with $1 \%$ toluidine blue in borax, and examined with a Nikon Optiphot Light Microscope. Histological sections were obtained at the level of the prosencephalon and rhombencephalon as judged by the presence of the developing optic and otic vesicles, respectively. The prosencephalic neuroectoderm was further subdivided into dorsal and ventral regions. For each region, morphometric analyses of mean cross-sectional area (MXA), mean cross-sectional cell number (MXN) and assessments of mitotic 


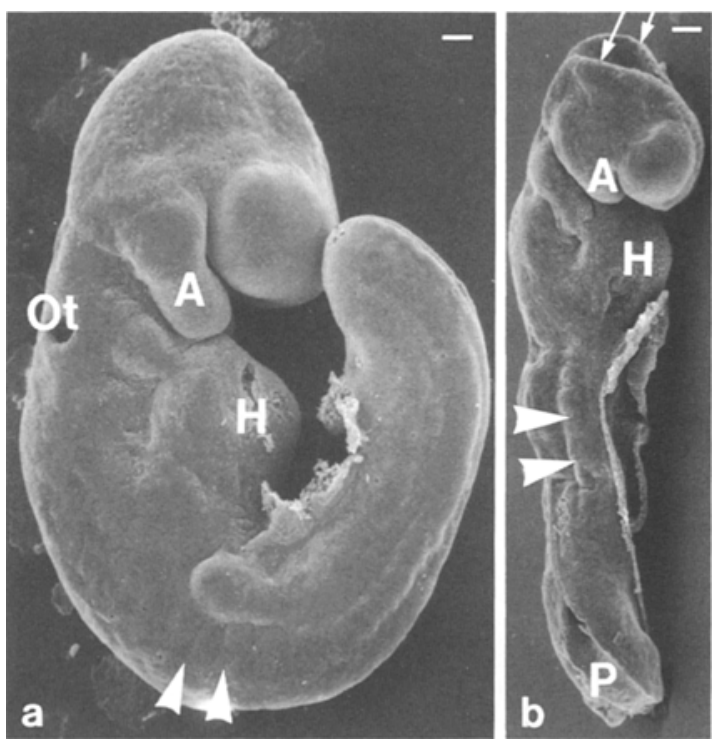

Fig. 2 a, b. Scanning electron micrographs of mouse embryos of various groups after 24 h of culture (end of Period I). a Embryo cultured in control medium (Group A) showing complete rotation, regular formation of somites (arrowheads), and closed cranial neural tube. $\mathrm{A}=$ first visceral arch; $\mathrm{Ot}=$ otic placode; $\mathrm{H}=$ heart. Scale bar $=0.1 \mathrm{~mm}$. b Embryo cultured in $32 \mathrm{mmol} / \mathrm{L} \mathrm{D}, \mathrm{L}$,-beta-hydroxybutyrate-containing medium (Group B and C) showing incomplete rotation, irregular somite formation (arrowheads), open cranial neural tube (arrows) and an exaggerated posterior neuropore (P) with flared neural folds. A = first visceral arch; $\mathrm{H}=$ heart. Scale bar $=0.1 \mathrm{~mm}$

index were conducted. To avoid counting cells twice, measurements were performed on eight sections of $1 \mu$ in thickness and $5 \mu$ apart, for three-nine embryos in each of the three groups (i.e. Group A, B, and $\mathrm{C}$ ), at each of the four time points of Period II.

\section{Morphometric analyses of mean cross-sectional area $(M X A)$}

Morphometric analyses were made by first photographing the sections with a Nikon AFX Camera and Nikon Optiphot Microscope System. Then each negative was mounted on a Durst Laborator S45 EM Enlarger and the image was enlarged 10 times and projected on a Numonics 2210 Digitizer Tablet. Using Sigma Scan Scientific Measurement System version 3.01 (Jandel Scientific, Sausalito, Calif., USA), the region of the neuroepithelium was digitized and input automatically into an IBM Personal System/2 Model 30 PC Computer. The data, expressed as $\mu \mathrm{m}^{2}$ were averaged and corrected for magnifications made by the microscope, camera and enlarger.

At the level of the prosencephalon, the neuroepithelium was delineated into dorsal and ventral regions as illustrated in Figure 1a. First, a horizontal line joining the points of inflection $\mathrm{X}$ and $\mathrm{X}^{\prime}$, where the neuroepithelium gives rise to the optic stalk and optic cup on symmetrical sides of the neural tube was made. Then, two perpendicular lines were drawn from $X$ and $X^{\prime}$ respectively tointersect with the ventral side of the neuroepithelium at $Y$ and $Y^{\prime}$. Therefore, the dorsal region was defined as the portion of neuroepithelium dorsal to line $X X^{\prime}$ and similarly, the ventral region was the portion between points $Y$ and $Y^{\prime}$. Analyses within the region of the optic vesicle and the optic stalk themselves were omitted at 12,24 and $36 \mathrm{~h}$ time points of Period II. However, at $0 \mathrm{~h}$ of Period II, no subdivisions of the neuroepithelium were made and assessments were obtained from the entire neuroectoderm including both the opticstalks and vesicles since these structures were too rudimentary and were technically difficult to be properly defined at this stage of development.

At the level of the rhombencephalon, the entire region of the neuroepithelium was included at all time points as illustrated in Figure $1 b$. Symmetry of the histological sections was determined by the symmetrical appearance of morphological features such as the optic stalk, optic vesicles, optic cup, lens placode, otic vesicle and vestibulocochlear ganglion.

\section{Analyses of mean cross-sectional cell number $(M X N)$}

Cell number was determined by counting the number of nuclei within the neuroepithelium in sections as prepared for morphometric analyses. Since neuroepithelial cells are mononucleated, the number of nuclei was indicated as cell number. In addition, because sections were only $1 \mu$ in thickness and $5 \mu$ apart, whereas neuroepithelial cell nuclei are approximately $4 \mu$ in diameter, the possibility of counting the same nucleus in two sections was eliminated.

\section{Analyses of mitotic index}

Mitotic figures were counted in sections as prepared for morphometric analyses. Mitotic index was calculated as the percentage of cells undergoing mitosis in the total cell population [17]. Mitotic figures included late prophase (absence of a nuclear membrane). metaphase, anaphase and telophase. Adjacent telophases were counted as one mitotic figure.

\section{Statistical analysis}

All data were statistically analysed using an ANOVA.

\section{Results}

After $24 \mathrm{~h}$ of culture (end of Period I), embryos grown in control medium exhibited normal growth and development for this time period [10]. Sixteen to 17 somite pairs were present, cranial neural folds were closed, and the posterior neuropore was open, but normal in appearance (Fig. 2a). In contrast, $100 \%$ of embryos grown in the presence of $32 \mathrm{mmol} / \mathrm{l} \mathrm{BOHB}$ were growth retarded, had open cranial neural folds that were widely spaced, abnormal opening of the posterior neuropore, which was too long and wide, and irregularly shaped somites (Fig. 2b). However, after the $36 \mathrm{~h}$ recovery period, recovery embryos (Group B) approximated similarly matched controls (Group A) in gross morphology including closure of the anterior and posterior neuropores (Figs. $3 \mathrm{a}, \mathrm{b}$ ). These results differed from those observed in embryos continuously exposed to the ketone body (Group C) which exhibited a 20 and $75 \%$ rate of abnormal closure of the cranial and caudal neuropores, respectively (Fig. 3c).

At the end of Period I (i.e. 0 h of Period II), Group A embryos (control group) possessed distinguishable rudiments of the optic as well as the otic vesicles. The optic vesicle was an evagination of the neuroepithelium of the diencephalic portion of the prosencephalon, whereas the developing otic pit marked the level rhombencephalic neuroectoderm. The mean cross-sectional area (MXA) of the neuroepithelium at these two levels was 


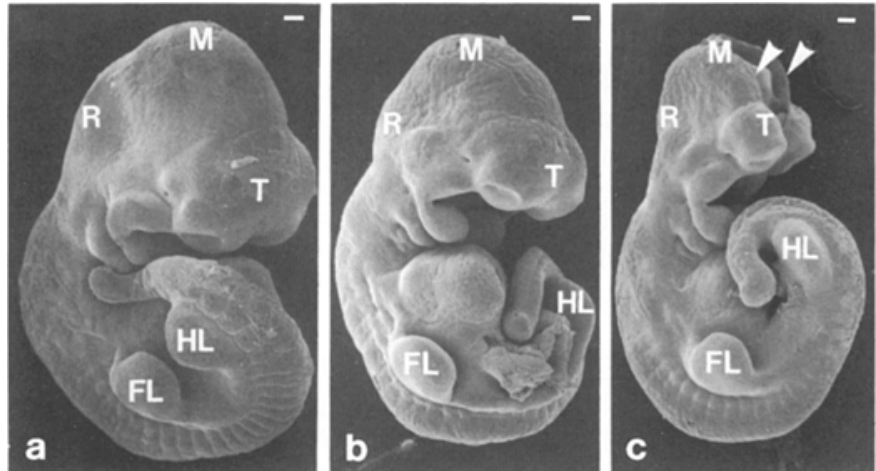

Fig.3a-c. Scanning electron micrographs of mouse embryos of various groups at the end of Period II ( 36 -h time point of Period II). a Embryo cultured in control medium (Group A) showing normal development of the brain vesicles including the telencephalon $(T)$, mesencephalon (M) and thombencephalon (R). Forelimb bud (FL) and hindlimb bud (HL). Scale bar $=0.1 \mathrm{~mm}$. b Embryo exposed to $\mathrm{D}, \mathrm{L},-$-beta-hydroxybutyrate for $24 \mathrm{~h}$ and then transferred to control medium (Group B: recovery group) showing various morphological features that approximated that of embryos grown in control medium. Telencephalon (T); mesencephalon (M); rhombencephalon (R); forelimb bud (FL); hindlimb bud (HL). Scale bar $=0.1 \mathrm{~mm}$. c Embryo exposed to D,L,-beta-hydroxybutyrate throughout both culture periods (Group C) showing an open anterior neural tube (arrowheads) associated with telencephalic and rhombencephalic hypoplasia. Telencephalon (T); mesencephalon (M); rhombencephalon (R); forelimb bud (FL); hindlimb bud (HL). Scale bar $=0.1 \mathrm{~mm}$

$(9.57 \pm 0.24) \times 10^{4} \mu \mathrm{m}^{2}$ and $(2.79 \pm 0.15) \times 10^{4} \mu \mathrm{m}^{2}$,respectively (Table 1$)$. At various time points during Period II (i.e. 12, 24 and $36 \mathrm{~h}$ ), MXA of the neuroepithelium at the level of the developing optic and otic vesicles increased and this growth was particularly prominent at the $24 \mathrm{~h}$ time point. A similar pattern of growth was observed when the dorsal and ventral regions of the prosencephalic neuroepithelium were examined separately.

In Group B and C embryos, there was a significant reduction $(p<0.05)$ in MXA at the conclusion of Period I (i.e. $24 \mathrm{~h}$ exposure to $\mathrm{BOHB}$ ) in both regions of the neuroectoderm when compared with controls. Upon continuous exposure to the ketone body during Period II (Group C embryos), this area continued to be only 53$63 \%$ of control values (Table 1). However, the dorsal region of the neuroepithelium at the level of the developing optic vesicles was more severely affected than that of the ventral region, since there was only a 19\% decrease in the area of the ventral region, whereas there was as much as a $52 \%$ reduction in the dorsal region after $36 \mathrm{~h}$ of Period II.

Group B embryos (recovery group) exhibited better growth and development during the entire period of recovery (Period II) (Table 1) than the continuously treated Group C. At the $12 \mathrm{~h}$ time point of Period II, MXA was $65 \%$ of that in controls and at 24 and $36 \mathrm{~h}$, this value was $75 \%$ for both the prosencephalic and rhombencephalic regions. This tendency to improve rendered the value of MXA significantly greater $(p<0.05)$ than that of the continuously exposed Group C, but, nevertheless, less than that observed in the control Group A. When the dorsal and ventral regions of the prosencephalic neuroectoderm were examined separately, it was observed that the ventral region had undergone complete catch-up growth by $36 \mathrm{~h}$ of Period II, since values in both Group A and B were comparable, whereas the dorsal region had only displayed partial recovery, i.e. the value was $71 \%$ of controls.

The mean cross-sectional cell number (MXN) reflected the same pattern of growth and development as that observed with morphometric analysis. MXN in the prosencephalic and rhombencephalic neuroepithelium of Group A embryos averaged 748 and 221 respectively, at the end of the first $24 \mathrm{~h}$ of culture (Period I). During Period II, with progression of time, there was a steady increase in MXN in all regions examined (Table 2).

When embryos were exposed to BOHB for $24 \mathrm{~h}$, that is, at the conclusion of Period I, MXN was decreased by $20 \%$ and $30 \%$ for the prosencephalic and rhombencephalic regions of the neuroepithelium respectively. Upon continuous exposure to the ketone body, as in Group C, MXN was further decreased, and was only $44 \%$ of control values in the prosencephalic and rhombencephalic regions at $36 \mathrm{~h}$ of Period II (Table 2). In addition, paralleling the phenomenon that was observed in the assessment of MXA, MXN was more severely affected in the dorsal region of the prosencephalic neuroepithelium than it was in the ventral region. This difference was noted at all time points of Period II such that by $36 \mathrm{~h}$ of this period, the accumulation of cells in Group C embryos was only $37 \%$ of control values in the dorsal area, whereas it was $70 \%$ in the ventral area.

When embryos were allowed to recover from dysmorphogenic exposure to $32 \mathrm{mmol} / \mathrm{l}$ BOHB (i.e. Group B embryos), they exhibited partial recovery in MXN. However, even at the end of Period II (i.e. recovery period), values for $\mathrm{MXN}$ in the recovery group were less than those in the control group, but greater than values observed in the continuously treated Group C (Table 2 ). This partial recovery was observed in both the prosencephalic as well as the rhombencephalic neuroectoderm. Furthermore, differences in the dorsal and ventral regions of the prosencephalic neuroectoderm were once again present and the ventral region demonstrated complete catch-up growth while the dorsal region remained reduced.

Due to this increase in MXN which paralleled an elevation in MXA in the neuroectoderm of Group B (recovery group) embryos, the mitotic index was examined in all three groups. In Group A, control embryos, the mitotic indices were $8.7 \%$ and $8.6 \%$ respectively for the prosencephalic and rhombencephalic neuroepithelium at the end of the first $24 \mathrm{~h}$ of culture. This rate of proliferation gradually decreased with further development of the embryos, that is during the next $36 \mathrm{~h}$ of culture (Fig. 4).

Exposure to BOHB for 24 h caused a $44 \%$ and $49 \%$ reduction in mitotic indices in the prosencephalic and rhombencephalic neuroectoderm, respectively. This decrease in rate of mitosis was unaccompanied by any significant increase in cell death as judged by no apparent accumulation of pyknotic debris in the histological sections at any time point. Upon continuous exposure (i.e. Group C embryos) to the ketone body, a 35-39\% reduction in the rate of proliferation at the $12 \mathrm{~h}$ time point of Period II was observed in all regions of the neuroepi- 
Table 1. Demonstration of capacity of mouse embryos to recover in mean cross sectional area from a growth retarding effect of D,L,-betahydroxybutyrate in culture

\begin{tabular}{|c|c|c|c|c|c|}
\hline $\begin{array}{l}\text { Time } \\
\text { (b) }\end{array}$ & Group & $\begin{array}{l}\text { Prosen } \\
\text { Dorsal }^{b}\end{array}$ & $\begin{array}{l}\text { Prosen } \\
\text { Ventral }^{\mathrm{b}}\end{array}$ & $\begin{array}{l}\text { Prosen } \\
\text { Total }^{\mathrm{b}}\end{array}$ & $\begin{array}{l}\text { Rhomben } \\
\text { Total }^{\mathrm{b}}\end{array}$ \\
\hline 0 & $\begin{array}{l}\mathrm{A} \\
\mathrm{B} \\
\mathrm{C}\end{array}$ & & & $\begin{array}{l}9.57 \pm 0.24(6) \\
7.73 \pm 0.26(4)^{c} \\
7.73 \pm 0.26(4)^{c}\end{array}$ & $\begin{array}{l}2.79 \pm 0.15(5) \\
2.35 \pm 0.16(4)^{c} \\
2.35 \pm 0.16(4)^{c}\end{array}$ \\
\hline 12 & $\begin{array}{l}\mathrm{A} \\
\mathrm{B} \\
\mathrm{C}\end{array}$ & $\begin{array}{l}6.21 \pm 0.27(9) \\
3.85 \pm 0.25(7)^{\circ} \\
3.65 \pm 0.05(5)^{\circ}\end{array}$ & $\begin{array}{l}2.50 \pm 0.07(9) \\
1.80 \pm 0.14(7)^{c} \\
1.67 \pm 0.16(5)^{c}\end{array}$ & $\begin{array}{l}8.71 \pm 0.32(9) \\
5.64 \pm 0.35(7)^{\mathrm{c}} \\
5.32 \pm 0.18(5)^{\mathrm{c}}\end{array}$ & $\begin{array}{l}5.69 \pm 0.23(9) \\
3.83 \pm 0.19(7)^{\mathrm{c}} \\
3.29 \pm 0.25(7)^{\mathrm{c}}\end{array}$ \\
\hline 36 & $\begin{array}{l}\text { A } \\
\text { B } \\
\text { C }\end{array}$ & $\begin{array}{l}18.73 \pm 0.57(7) \\
13.31 \pm 0.92(6)^{\mathrm{c}} \\
9.00 \pm 0.87(9)^{c_{1} d}\end{array}$ & $\begin{array}{l}4.08 \pm 0.18(7) \\
3.86 \pm 0.29(6) \\
3.29 \pm 0.24(9)^{c}\end{array}$ & $\begin{array}{l}22.81 \pm 0.70(7) \\
17.17 \pm 1.01(6)^{\mathrm{c}} \\
12.28 \pm 1.07(9)^{\mathrm{c}, \mathrm{d}}\end{array}$ & $\begin{array}{l}17.26 \pm 0.66(7) \\
13.15 \pm 0.65(6)^{c} \\
9.09 \pm 0.61(9)^{c, d}\end{array}$ \\
\hline
\end{tabular}

${ }^{a}$ Time represents the period (Period II) following $24 \mathrm{~h}$ of culture of embryos in control medium (Group A) or medium containing $32 \mathrm{mmol} / \mathrm{l} \mathrm{D}, \mathrm{L}$,-beta-hydroxybutyrate (Group B and C). At the beginning of Period II, i. e. 0 time, Group A embryos were maintained in control medium; Group B embryos were transferred to control medium and therefore represent the recovery group; Group C embryos were transferred to fresh medium containing $32 \mathrm{mmol} / \mathrm{l} \mathrm{D}, \mathrm{L}$,beta-hydroxybutyrate and therefore represent the continuously exposed group.
${ }^{b}$ Mean cross-sectional area was determined in different regions of the neuroepithelium; the prosencephalic neuroectoderm (prosen total) and the rhombencephalic neuroectoderm (rhomben total). The former was further subdivided into dorsal and ventral areas. All values were expressed as $\left[\right.$ mean $\left.\left(\mu \mathrm{m}^{2}\right) \pm \operatorname{SEM}(n)\right] \times 10^{4}$.

$c=p<0.05$ when compared with Group A (ANOVA);

$d=p<0.05$ when compared with Group $B$

Table 2. Demonstration of the capacity of mouse embryos to recover in mean cross-sectional cell number from a growth retarding effect of $\mathrm{D}, \mathrm{L}$, -beta-hydroxybutyrate in culture

\begin{tabular}{|c|c|c|c|c|c|}
\hline $\begin{array}{l}\operatorname{Time}^{a} \\
\text { (b) }\end{array}$ & Group $^{a}$ & $\begin{array}{l}\text { Prosen } \\
\text { Dorsal }^{b}\end{array}$ & $\begin{array}{l}\text { Prosen } \\
\text { Ventral }\end{array}$ & $\begin{array}{l}\text { Prosen } \\
\text { Total }\end{array}$ & $\begin{array}{l}\text { Rhomben } \\
\text { Total }^{\mathrm{b}}\end{array}$ \\
\hline 0 & $\begin{array}{l}\mathrm{A} \\
\mathrm{B} \\
\mathrm{C}\end{array}$ & & & $\begin{array}{l}748.06 \pm 35.39(4) \\
596.63 \pm 32.33(4)^{c} \\
596.63 \pm 32.33(4)^{c}\end{array}$ & $\begin{array}{l}221.65 \pm 10.29(5) \\
154.50 \pm 9.05(4)^{c} \\
154.50 \pm 9.05(4)^{c}\end{array}$ \\
\hline 12 & $\begin{array}{l}\text { A } \\
\text { B } \\
\text { C }\end{array}$ & $\begin{array}{l}452.25 \pm 31.77(5) \\
268.25 \pm 22.03(5)^{c} \\
304.33 \pm 16.05(3)^{c}\end{array}$ & $\begin{array}{l}196.65 \pm 8.38(5) \\
143.20 \pm 11.82(5)^{c} \\
143.67 \pm 16.10(3)^{c}\end{array}$ & $\begin{array}{l}648.90 \pm 37.61(5) \\
411.45 \pm 30.28(5)^{\mathrm{c}} \\
448.00 \pm 29.95(3)^{\mathrm{c}}\end{array}$ & $\begin{array}{l}492.86 \pm 44.21(5) \\
283.81 \pm 28.83(6)^{c} \\
210.60 \pm 22.21(5)^{c}\end{array}$ \\
\hline 36 & $\begin{array}{l}\mathrm{A} \\
\mathrm{B} \\
\mathrm{C}\end{array}$ & $\begin{aligned} 1812.67 & \pm 109.59(3) \\
1083.92 & \pm 100.57(3)^{c} \\
677.45 & \pm 130.60(5)^{c d}\end{aligned}$ & $\begin{array}{l}416.67 \pm 38.20(3) \\
435.08 \pm 47.07(3) \\
293.95 \pm 31.65(5)^{c, d}\end{array}$ & $\begin{array}{l}2232.33 \pm 130.18(3) \\
1519.00 \pm 95.67(3)^{\mathrm{c}} \\
971.40 \pm 154.55(5)^{\mathrm{c} d}\end{array}$ & $\begin{array}{l}1848.88 \pm 39.24(6) \\
1421.46 \pm 70.73(6)^{c} \\
818.89 \pm 61.93(9)^{\mathrm{c}, \mathrm{d}}\end{array}$ \\
\hline
\end{tabular}

a Time represents the period (Period II) following $24 \mathrm{~h}$ of culture of embryos in control medium (Group A) or medium containing $32 \mathrm{mmol} / \mathrm{D}, \mathrm{L}$,-beta-hydroxybutyrate (Group B and C). At the beginning of Period II, i.e. 0 time, Group A embryos were maintained in control medium; Group B embryos were transferted to control medium and therefore represent the recovery group; Group C embryos were transferred to fresh medium containing $32 \mathrm{mmol} / \mathrm{l} \mathrm{D}, \mathrm{L}$,beta-hydroxybutyrate and therefore represent the continuously exposed group.

thelium (Fig. 4). However, by $24 \mathrm{~h}$ of Period II, the rate of mitosis of Group C embryos was comparable to levels observed in Group A control embryos. At $36 \mathrm{~h}$ of Period II, the proliferative rate in Group C embryos was reduced in the rhombencephalic neuroectoderm and there was a trend towards a reduction in both dorsal and ventral regions of the prosencephalic neuroectoderm. However, the reduction in rate of mitosis at $36 \mathrm{~h}$ of Period II was less severe than that present at 0 or $12 \mathrm{~h}$ of Period II.

Embryos that were exposed to BOHB for $24 \mathrm{~h}$ (which resulted in a $44-49 \%$ reduction in the mitotic index), but
${ }^{\mathrm{b}}$ Mean cross-sectional cell number was determined in different regions of the neuroepithelium; the prosencephalic neuroectoderm (prosen total) and the rhombencephalic neuroectoderm (rhomben total). The former was further subdivided into dorsal and ventral areas. All values were expressed as mean $\pm \operatorname{SEM}(n)$.

$c=p<0.05$ when compared with Group A (ANOVA);

$\mathrm{d}=p<0.05$ when compared with Group $\mathrm{B}$

subsequently allowed to recover (i.e. Group B), demonstrated a less severe reduction in the mitotic index at $12 \mathrm{~h}$ of Period II than those from Group C (Fig. 4). Thus, the values for the mitotic index in the control Group $\mathrm{A}$ and recovery Group B were comparable for the rhombencephalic neuroectoderm and the value of Group B was approximately $80 \%$ of controls for the dorsal and ventral regions of the prosencephalic neuroectoderm. At $24 \mathrm{~h}$ of Period II, there was an increase in the rate of mitosis in Group B above that of normal control values exhibited by Group A. For example, in the rhombencephalic neuroec- 


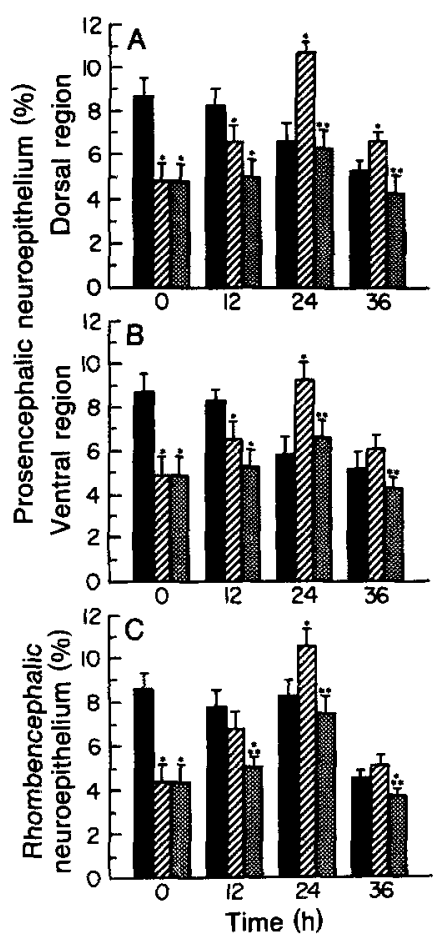

Fig.4a-c. Mitotic indices at three different regions of the neuroectoderm of mouse embryos of various groups during Period II. Assessment of mitotic index in Group A (control; solid bar), B (recovery; hatched bar) and $\mathrm{C}$ (continuously exposed; stippled bar) at three different regions: a dorsal region of the prosencephalic neuroectoderm; $\mathbf{b}$ ventral region of the prosencephalic neuroectoderm; c rhombencephalic neuroectoderm, during $0,12,24$ and $36 \mathrm{~h}$ time points of Period II. Note that exposure to D,L,-beta-hydroxybutyrate led to a $44-49 \%$ reduction in the mitotic index. Twelve hours of recovery allowed the value for the mitotic index of Group B to approach control levels. At $24 \mathrm{~h}$, maximum elevation in rate of proliferation was observed which was higher than control values, and at $36 \mathrm{~h}$, this overshooting in excess of normality reverted to control levels. This general pattern was noted in all regions examined, but the degree of overshooting was variable among the different regions. $*=p<0.05$ when compared with Group A; $* *=p<0.05$ when compared with Group B (ANOVA)

toderm, there was a $28 \%$ increase over normality and at the dorsal and ventral regions of the prosencephalic neuroectoderm, there was a $61 \%$ elevation in proliferative rates. At $36 \mathrm{~h}$ of Period II, an increase $(25 \%)$ remained in the mitotic index in the dorsal part of the prosencephalic neuroectoderm and a trend toward overshooting normality was present in the ventral prosencephalic and rhombencephalic regions of the neuroectoderm.

\section{Discussion}

Previous studies have shown that the ketone body $\mathrm{D}, \mathrm{L},-$ beta-hydroxybutyrate $(\mathrm{BOHB})$ produces neural tube closure and craniofacial defects in mouse and rat embryos exposed for 24 to $48 \mathrm{~h}$ to the compound during early stages of neurulation ( $0-10$ somites) [12-14]. In the case of neural tube abnormalities, the defects were considered severe since the cranial and caudal neural folds failed to elevate completely and fuse. Thus, this developmental event had missed its 'critical' period. However, when mouse embryos were exposed to $\mathrm{BOHB}$ for $24 \mathrm{~h}$ and then placed in an environment free of the teratogen, cranial and caudal neural tube closure occurred in more than $95 \%$ of the embryos over the next $24 \mathrm{~h}$ such that these conceptuses had 'recovered' [6].

The present study indicates that although the embryos recovered morphologically, histological recovery was only partial and deficiencies in cell number remained in the cranial neuroepithelium. Whether or not these deficiencies would have existed at birth is not known since embryos cannot be cultured to that point, but the fact that mitotic activity essential for recovery, had peaked prior to the end of culture, suggests that an exposure to severe ketosis early in gestation (weeks 3-4 in the human) may lead to neurological deficits later in development. Reports of low brain weight in infants of diabetic mothers $[7,8,18]$ and the associations of maternal ketoacidosis $[19,20]$ and maternal diabetes [21] with neurological and psychological impairments in infants postnatally, support this hypothesis.

Although total recovery occurred only in the ventral region of the forebrain, the dorsal region and the hindbrain showed better growth in recovering embryos than that exhibited by embryos continuously exposed to $\mathrm{BOHB}$. The mechanism for this improvement is similar to that observed in embryos exposed to cytotoxic agents prior to organogenesis [1] or to that observed in the neuroepithelium of embryos exposed to such agents later in development [3]. Thus, increased mitotic activity appears to be a prerequisite for catch-up growth in all these instances.

The fact that neural tube closure was successfully accomplished in recovering embryos despite being delayed by $24 \mathrm{~h}$ may be related to the generalized effects of $\mathrm{BOHB}$. The ketone appears to affect all cells and tissues of the mouse embryo in a non-cytotoxic manner [22], such that gross morphological events such as neural tube closure may be delayed in a synchronous fashion. Then, when the period of perturbation is over, morphogenesis resumes. Such a hypothesis is supported by recent results with mouse mutants having spina bifida in which the defect could be eliminated by restoring synchronous development of the neural tube with surrounding structures [23]. However, it is clear from the present studies that subtle alterations in specific cell populations remain after exposure to BOHB, such that total recovery does not occur.

The capacity for recovery to occur during the period of neurulation raises concern about the manner of scoring malformations in whole embryo culture systems. For example, using the culture technique, rodent embryos can be maintained only to the early limb bud stages (3040 somites) of development [9]. Therefore, insufficient time may be available for embryos to recover from an insult resulting in an erroneous assessment of the teratogenicity of a compound. Thus, there is a requirement for caution in extrapolating data obtained in vitro to the in vivo situation.

Acknowledgement. This work was supported by National Institute of Health Grant HD 19593. 


\section{References}

1. Snow MHL, Tam PPL (1979) Is compensatory growth a complicating factor in mouse teratology? Nature 279: 555-557

2. Shimada M, Langman J (1970) Repair of the external granular layer of the hamster cerebellum after prenatal and postnatal administration of methylazoxymethanol. Teratology 3: 119-134

3. Langman J, Cardell EL (1977) Cell degeneration and recovery of the fetal mammalian brain after a chemical insult. Teratology 16: $15-30$

4. D'Amato CJ (1982) Regeneration and recovery in the fetal nervous system after radiation injury. Exp Neurol 76: 457-467

5. Beaudoin AR, Fisher DL (1981) An in vivo/in vitro evaluation of teratogenic action. Teratology 23: 57-61

6. Shum L, Sadler TW (1988) Embryonic catch-up growth after exposure to the ketone body D,L,-beta-hydroxybutyrate. Teratology 38: 369-379

7. Driscoll SG, Benirschke K, Curtis GW (1960) Neonatal deaths among infants of diabetic mothers. Am J Dis Child 100: 818-835

8. Gruenwald P (1966) Growth of the human fetus. II. Abnormal growth in twins and infants of mothers with diabetes, hypertension, or isoimmunization. Am J Obstet Gynecol 94: 1120-1132

9. Sadler TW (1979) Culture of early somite mouse embryos during organogenesis. J Embryol Exp Morphol 49:17-25

10. New DAT (1978) Whole-embryo culture and the study of mammalian embryos during organogenesis. Biol Rev 53: 81-122

11. Steele CE, New DAT (1974) Serum variants causing the formation of double hearts and other abnormalities in explanted rat embryos. J Embryol Exp Morphol 31: 707-719

12. Horton WE, Sadler TW (1983) Effects of maternal diabetes on early embryogenesis. Alterations in morphogenesis produced by the ketone body, $\beta$-hydroxybutyrate. Diabetes 32: 610-616

13. Lewis NJ, Akazawa S, Freinkel N (1983) Teratogenesis from $\beta$ hydroxybutyrate during organogenesis in rat embryo organ culture and enhancement by sub-teratogenic glucose. Diabetes 32 [Suppl]: 11A (Abstract)

14. Sheehan EA, Beck F, Clarke CA, Stanisstreet M (1985) Effects of $\beta$-hydroxybutyrate on rat embryos grown in culture. Experientia 41:273-275
15. Gomori $G$ (1955) Preparation of buffers for use in enzyme studies. In: Colowick SP, Kaplan NO (eds) Methods in enzymology, vol 1. Academic Press, New York, pp 138-144

16. Karnovsky MJ (1965) A formaldehyde-glutaraldehyde fixative of high osmolarity for use in electron microscopy. J Cell Biol 27: $137 \mathrm{~A}-138 \mathrm{~A}$

17. Leblond CP, Walker BE (1956) Renewal of cell populations. Physiol Rev 36: 255-276

18. Cardell BS (1953) The infants of diabetic mothers: a morphological study. Am J Obstet Gynecol 60: 834-853

19. Churchill AJ, Berendes HW, Nemore J (1969) Neuropsychological deficits in children of diabetic mothers. Am J Obstet Gynecol 105: 257-268

20. Stehbens JA, Baker GL, Kitchell M (1977) Outcome at ages 1, 3 , and 5 years of children born to diabetic women. Am J Obstet Gynecol 127: 408-413

21. Peterson MB, Pederson SA, Greisen G, Pederson JF, MolstedPederson L (1988) Early growth delay in diabetic pregnancy: relation to psychomotor development at age 4. Br Med J 296: 598600

22. Horton WE, Sadler TW (1985) Mitochrondrial alterations in embryos exposed to $\beta$-hydroxybutyrate in whole embryo culture. Anat Rec 213: 94-101

23. Copp AJ, Crolla JA, Brook FA (1988) Prevention of spinal neural tube defects in the mouse embryo by growth retardation during neurulation. Development 104:297-303

Received: 29 May 1990

and in revised form: 2 October 1990

Dr. T.W. Sadler

Laboratories for the study of Birth Defects

and Developmental Biology

Department of Cell Biology and Anatomy

School of Medicine

312 Taylor Hall

University of North Carolina

Chapel Hill, NC 27599-7090

USA 